\title{
Dynamic Simulation to identify Cost-Optimal Energy Requirements for the Italian Building Stock
}

\author{
Vincenzo Corrado, Ilaria Ballarini, Giovanna De Luca, Elisa Primo \\ Politecnico di Torino, Turin, Italy
}

\begin{abstract}
The present work is aimed at advising the update of Italian law by identifying cost-optimal levels of minimum energy performance requirements for buildings. The scope is to investigate the suitability of simplified methods, such as the one officially adopted by Italian regulations, to determine the cost-optimal levels of energy performance. To this purpose, for a residential building, a cost optimal analysis was performed through detailed dynamic simulation and the NSGA-II multi-objective optimization tool, as implemented in DesignBuilder software. The results, presented in terms of "cost-optimal packages of measures", show that different optimization methods lead to identify different energy efficiency technologies as cost-optimal measures.
\end{abstract}

\section{Introduction}

\section{The comparative methodology framework}

In the aim of promoting cost-effective improvement of the energy performance of buildings, the Guidelines (European Union, 2012a) accompanying the Commission Delegated Regulation (EU) No 244/2012 (European Union, 2012b), supplementing Directive 2010/31/EU (European Union, 2010) set out a comparative methodology framework for calculating cost-optimal levels of minimum energy performance requirements for buildings. Even if the Guidelines are not legally binding as the Regulation, they provide relevant additional information to facilitate the application of the costoptimal methodology by the Member States.

For the purpose of the cost-optimal calculation and in order to achieve reliable results, the Guidelines recommend to perform the calculations using a detailed dynamic simulation method. Nevertheless, not representing an obligation for Member States, Italy decided to determine the cost-optimal levels of minimum energy performance requirements for buildings by means of the monthly quasi-steady-state method. It was coupled with the cost-optimization procedure based on a sequential search-optimization technique considering discrete options or levels of energy efficiency measures, as deeply described in Corrado et al. (2014a).

Regarding the calculation of the global cost in terms of net present value, the comparative methodology framework prescribes evaluation of cost-optimal levels for both macroeconomic and financial viewpoints, but each Member States can determine which of these calculations is to become the national benchmark for the assessment of national minimum energy performance requirements.

\section{Optimization models}

In general terms, optimization aims to find one or more solutions which minimize or maximize one or more objective functions (Sharif and Hammad, 2019). In building performance simulation, the term "optimization" generally refers to an automated process combining a numerical simulation program and an optimization tool, based on one or several optimization algorithms and strategies (Nguyen et al., 2014).

Depending on the considered number of objective functions, optimization problems can be classified as single-objective optimization or multi-objective optimization.

The single-objective approach allows to optimize only one objective function in an optimization run, whereas a multi-objective optimization involves multiple objective functions. In real-world building design problems are related to numerous criteria and constraints simultaneously (i.e. minimum energy consumption vs minimum construction cost, minimum energy consumption vs maximum thermal comfort, etc.). Therefore, multi-objective optimization results, in many cases, more effective and relevant than the singleobjective one even if its solution is more difficult. Multiobjective optimization identifies a set of acceptable tradeoff optimal solutions, called Pareto front.

According to Si et al. (2019), the optimization algorithms commonly used to solve building energy optimization problems can be generally classified into three groups: hybrid algorithms, direct search algorithms and heuristic algorithms. As many reviews highlighted (Evins, 2013; Harkouss et al., 2018; Machairas et al., 2014; Nguyen et al., 2014), in building energy optimization the most adopted algorithms are the heuristic ones, accounting for about $60 \%$, with a great predominance of the Nondominated Sorting Genetic Algorithm (NSGA) II algorithm (Longo et al., 2019).

The comparison of NSGA II's performance to other six multi-objective algorithms supports its frequency of employment as it results according to Hamdy et al. (2016) one of the best multi-objective algorithm, only preceded by Two-Phase Optimization Genetic algorithm. 


\section{Objectives of the work}

The present work follows the contribution to the research activity for Italian Ministry of Economic Development (2018), defining cost-optimal levels of minimum energy performance requirements for Italian reference buildings.

The study aims to validate the suitability of monthly quasi-steady-state method coupled with a sequential search-optimization technique to perform the costoptimal analysis and discusses the reasons of the discrepancies from the simulation-based optimization method coupling a detailed dynamic simulation model and a multi-objective optimization tool. The reason for choosing a quasi-steady-state method is that it is the official calculation method specified in Italian standards (UNI/TS 11300) and required by law.

\section{Methods}

\section{Assessment procedure}

According to the basic requirements given in European Directive 2010/31/EU (EPBD recast) and its supplements, the comparative methodology to calculate cost-optimal levels of minimum energy performance requirements includes the following steps:

- definition of reference buildings;

- identification of energy efficiency measures, based on renewable energy sources or packages/variants of such measures for each reference building;

- calculation of the primary energy demand resulting from the application of measures and packages of measures to a reference building;

- calculation of the global cost in terms of net present value for each reference building;

- derivation of a cost-optimal level of energy performance for each reference building.

In both simulation-based optimization models applied in the present work, economic indicators were evaluated according to EN 15459 (European Committee for Standardization, 2017). The financial calculation was adopted. The EN 15459 economic evaluation procedure is based on the net present value (global costs) calculation, considering the initial investment, the sum of the annual costs for each year (energy, maintenance, operation and any additional costs), the extraordinary replacement of systems and components, the final value, and the costs of disposal, as appropriate. All costs are actualized to the starting year.

\section{Optimization from quasi-steady-state calculation method}

The cost-optimization procedure couples the monthly quasi-steady-state (QSS) method and a sequential searchoptimization technique. The single objective in QSS is global cost, as specified in EN 15459.

The quasi-steady-state calculation method (Italian Organisation for Standardisation, 2014) balances heat losses (transmission and ventilation) and heat gains (solar and internal) assessed in monthly average conditions. The introduction of a utilization factor, considering the time overlap between transmission plus ventilation heat losses and solar plus internal heat gains profiles, allows to take into account the dynamic effects on the net energy needs for space heating and space cooling. The utilisation factor depends on the time constant of the building, on the ratio of heat gains to heat losses, and on the occupancy/system management schedules.

The cost-optimization procedure, coupled with the simplified calculation method, pertains to the model developed by Christensen et al. (2006). Starting from a reference package of energy efficiency options, it identifies a sequence of "partial optimums" by changing one at a time all the parameters that characterize each energy efficiency measure. The configuration, reaching at each step the highest reduction in terms of global cost, becomes the next partial optimum.

\section{Optimization from detailed dynamic simulation model}

The simulation-based optimization method combines the detailed dynamic simulation model (DD) and a multiobjective optimization algorithm. The multiple objectives in $\mathrm{DD}$ are the global cost and the overall non-renewable primary energy demand.

The building energy performance is assessed by means of the DesignBuilder software, which adopts the EnergyPlus detailed energy simulation code. EnergyPlus is based on the heat balance model, with the following assumptions: the air in the thermal zone has a uniform temperature, the temperature of each surface is uniform, the long and shortwave irradiation is uniform, the surface irradiation is diffusive, and the heat conduction through the surfaces is one-dimensional.

The detailed dynamic simulation model is combined with the multi-objective optimization algorithm implemented in DesignBuilder software. It is the so-called NSGA-II, developed by Deb et al. (2002) as an elitist version of NSGA. As NSGA-II is a genetic algorithm, it is characterized by: a main loop iterating generation by generation, fitness evaluation and selection, crossover and mutation operators. In comparison with the normal genetic algorithm, NSGA-II introduces a series of modifications to its operators, mainly to its selection operator. In NSGA-II the best individuals, who will be used for reproduction, are not directly selected using the fitness values. NSGA-II identifies its best individuals according to a combination of the values obtained with the non-dominated sorting genetic and crowding distance algorithms.

\section{Application to a case study Description of the case study}

The case study is an apartment block built in the period from 1946 to 1960 . It is an Italian reference building selected within the IEE-TABULA project (Corrado et al., 2014 b), which is representative of the post-war apartment blocks in Italy. The case study is located in the Italian climatic zone E (Milano, 2404 HDD), considered the most representative for its geographic extension and amount of buildings. The picture and the main data of the case study are shown in Table 1. 
Table 1: Main data of the case study.

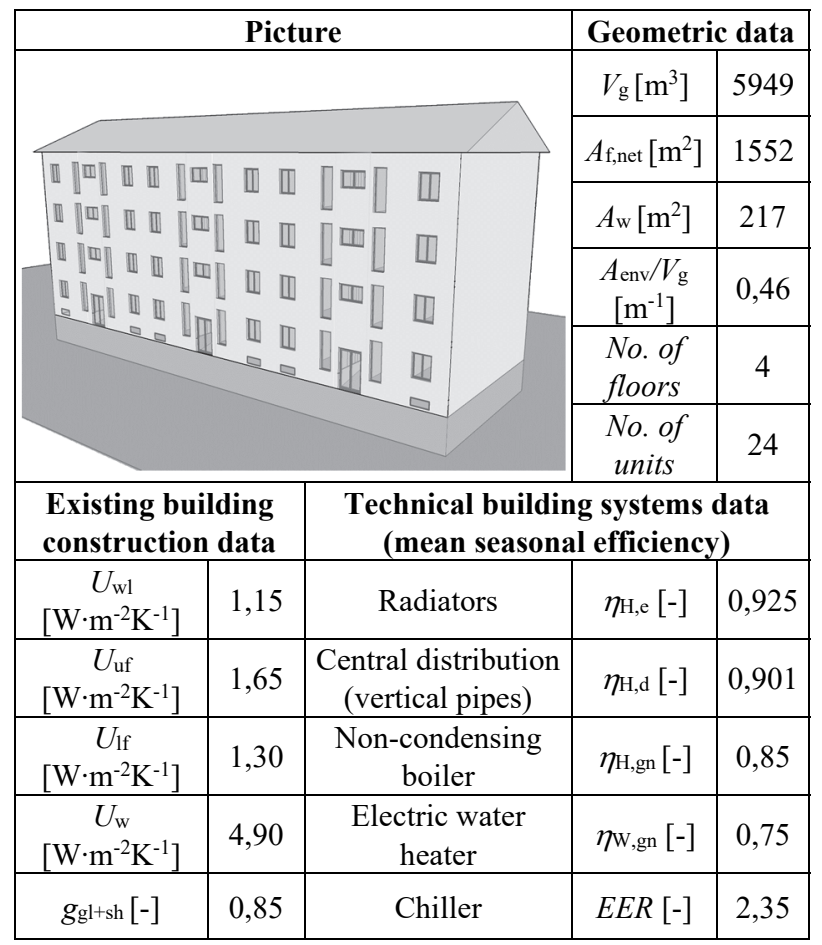

\section{Energy efficiency measures}

The energy efficiency measures (EEMs) tested for the case study are listed in Table 2.

For each measure, up to five energy efficiency options (EEOs) with increasing level of performance, have been defined. As concerns the building envelope insulation, the first option corresponds with taking no action, the second level refers to a U-value $20 \%$ higher than the value set by Italian legislation for the reference building since 2015 (Italian Ministry of Economic Development, 2015), the third and fourth level match the requirements for reference building respectively in force by 2015 and by 2019/2021. The fifth level, if applicable, represents a more performant solution.

The choice of not performing an energy efficiency measure, if cost-ineffective, was also included among the technical building systems options.

Regarding the renewable energy sources, solar collectors were used only for domestic hot water (DHW) and the technology of vacuum tube collectors with flat absorber was considered.

\section{Calculation assumptions and consistency options between models}

In order to compare the two energy performance calculation methods, some consistency options were adopted, as described below.

The hourly values of the outdoor air temperature, the solar radiation for each orientation, the water vapour pressure, the wind speed, and the equivalent sky temperature in Milan were derived from the weather database of the Italian Thermotechnical Committee (2016). The corresponding mean monthly climatic data were used in the quasi-steady-state calculation method.

Table 2: Energy efficiency measures (EEMs), and related options (EEOs).

\begin{tabular}{|c|c|c|c|c|c|c|c|}
\hline \multirow{2}{*}{\multicolumn{2}{|c|}{ EEM }} & \multirow[b]{2}{*}{ no. } & \multicolumn{5}{|c|}{ EEO } \\
\hline & & & 1 & 2 & 3 & 4 & 5 \\
\hline Wall insulation on external surface & $U_{\mathrm{wl}}\left[\mathrm{W} \mathrm{m} \mathrm{m}^{-2} \mathrm{~K}^{-1}\right]$ & 5 & $1,15\left(^{1}\right)$ & 0,36 & $0,30\left(^{2}\right)$ & $0,28\left(^{3}\right)$ & 0,19 \\
\hline or Wall insulation on cavity & $U_{\mathrm{wl}}\left[\mathrm{W} \mathrm{m} \mathrm{m}^{-2} \mathrm{~K}^{-1}\right]$ & 1 & 0,37 & - & - & - & - \\
\hline Upper floor insulation & $U_{\text {uf }}\left[\mathrm{W} \mathrm{m}{ }^{-2} \mathrm{~K}^{-1}\right]$ & 5 & $1,65\left({ }^{1}\right)$ & 0,46 & $0,37\left({ }^{2}\right)$ & $0,34\left(^{3}\right)$ & 0,29 \\
\hline Lower floor insulation & $U_{\text {lf }}\left[\mathrm{W} \mathrm{m} \mathrm{m}^{-2} \mathrm{~K}^{-1}\right]$ & 5 & $1,30\left(^{1}\right)$ & 0,63 & $0,52\left({ }^{2}\right)$ & $0,48\left(^{3}\right)$ & 0,32 \\
\hline Windows & $U_{\mathrm{w}}\left[\mathrm{W} \mathrm{\textrm {m } ^ { - 2 } \mathrm { K } ^ { - 1 } ]}\right.$ & 5 & $4,90\left(^{1}\right)$ & 2,30 & $1,90\left(^{2}\right)$ & $1,40\left(^{3}\right)$ & 1,10 \\
\hline Solar shading devices & $\mathrm{F}$ or $\mathrm{M}\left({ }^{4}\right)$ & 3 & Absent $\left({ }^{1}\right)$ & $\mathrm{F}$ & $\mathrm{M}$ & - & - \\
\hline Chiller & $E E R[-]$ & 2 & $2,35\left({ }^{1}\right)$ & 3,00 & - & - & - \\
\hline $\begin{array}{c}\text { Heat generator for space heating }\left({ }^{5}\right) \\
\text { Associated technology }\end{array}$ & $\eta_{\mathrm{H}, \mathrm{gn}}$ or $C O P[-]$ & 5 & $0,85\left({ }^{1}\right)$ & $\begin{array}{l}0,95 \\
\text { Standard } \\
\text { boiler, } \\
\text { radiators }\end{array}$ & $\begin{array}{c}1,00 \\
\text { Condensing } \\
\text { boiler, } \\
\text { fan coils }\end{array}$ & $\begin{array}{c}3,70 \\
\text { Heat } \\
\text { pump, } \\
\text { fan coils }\end{array}$ & $\begin{array}{c}4,10 \\
\text { Heat } \\
\text { pump, } \\
\text { fan coils }\end{array}$ \\
\hline $\begin{array}{l}\text { Heat generator for DHW } \\
\text { Associated technology }\end{array}$ & $\eta_{\mathrm{W}, \mathrm{gn}}[-]$ & 3 & $0,75\left(^{1}\right)$ & $\begin{array}{c}0,93 \\
\text { Standard } \\
\text { boiler }\end{array}$ & $\begin{array}{c}1,00 \\
\text { Condensing } \\
\text { boiler }\end{array}$ & - & - \\
\hline $\begin{array}{c}\text { Combined heat generator for space } \\
\text { heating and DHW }\left({ }^{5}\right) \\
\text { Associated technology }\end{array}$ & $\eta_{\mathrm{H}+\mathrm{W}, \mathrm{gn}}$ & 2 & $\begin{array}{l}0,93 \\
\text { Standard } \\
\text { boiler, } \\
\text { radiators }\end{array}$ & $\begin{array}{c}1,00 \\
\text { Condensing } \\
\text { boiler, } \\
\text { fan coils }\end{array}$ & - & - & - \\
\hline Thermal solar system & $A_{\text {coll }}\left[\mathrm{m}^{2}\right]$ & 5 & Absent $\left({ }^{1}\right)$ & 20 & 30 & 50 & 70 \\
\hline PV system & $W_{\mathrm{PV}}\left[\mathrm{kW}_{\mathrm{p}}\right]$ & 4 & Absent $\left({ }^{1}\right)$ & 7,2 & 9 & 10,8 & - \\
\hline $\begin{array}{l}\left({ }^{1}\right) \text { The option corresponds to the existing } \\
\left({ }^{2}\right) \text { Requirements for reference building in } \\
\left({ }^{4}\right) \mathrm{F} \text { = fixed louvres; } \mathrm{M}=\text { movable louvr }\end{array}$ & ilding without tak & & tion (see Tabl & ing system con & ce by 201 & & \\
\hline
\end{tabular}


The cost-optimal analysis was performed considering a continuous operation of the thermal systems. The temperature set-point was assumed constant on the whole day, at $20{ }^{\circ} \mathrm{C}$ in the heating season and at $26{ }^{\circ} \mathrm{C}$ in the cooling season, in both calculation methods.

The air flow rate by natural ventilation and the sensible internal heat gains were modelled in accordance with the UNI/TS 11300-1 technical specification (Italian Organisation for Standardisation, 2014). The mean monthly values, assumed in the quasi-steady-state method, were derived from the hourly profiles adopted in dynamic simulation.

The solar shadings were considered closed when the incident solar radiation on the transparent components was higher than $300 \mathrm{~W} \cdot \mathrm{m}^{-2}$. No shading reduction factor for external obstacles was considered.

The effect of thermal bridges was neglected in both models.

Only PID room control for heating system was considered among the EEOs.

The conversion coefficients to primary energy were assumed according to the Italian regulations (Italian Ministry of Economic Development, 2015).

The electricity from PV panels was considered as a reduction of the monthly electrical energy demand; the exported electrical energy was not considered.

In the global cost calculation, the following assumptions were applied:

- technical lifespan of building elements fixed at 30 years, of systems variable from 15 to 35 years,

- real interest rate fixed at $4 \%$,

- electricity and natural gas costs were derived from the Italian Regulatory Authority for Energy, Networks and Environment (ARERA) (Italian Ministry of Economic Development, 2018), and

- annual maintenance costs variable from $0 \%$ to $4 \%$ of the investment cost depending on the technology (European Committee for Standardization, 2017).

\section{Results}

The results of the two calculation methods (QSS, DD) are compared in terms of cost-optimal packages (COs) of energy efficiency measures, energy performance (overall non-renewable primary energy), and global cost over 30 years of building lifetime.

In addition, the cost optimal packages of measures derived from the quasi-steady-state method (CO-QSS) and from the dynamic simulation (CO-DD) respectively, were also assessed by means of the alternative energy performance calculation methods (see Table 3 ).

From the assessment of the CO-QSS and CO-DD solutions by exchanging the calculation method, it points out that CO-QSS evaluated through detailed dynamic simulation model, CO-QSS (DD), is both less expensive and energy intensive. On the other hand, the CO-DD assessed through QSS, CO-DD (QSS), results more expensive and more energy intensive. It appears clearly that QSS overestimates the energy use as well as the energy costs of about $80 \%$, as the initial investment costs are consistent between the two models.

Table 3: Cost-optimal packages of energy efficiency measures and calculation methods.

\begin{tabular}{|c|c|c|}
\hline \multirow{2}{*}{$\begin{array}{c}\text { Calculation method } \\
\text { for the energy } \\
\text { assessment }\end{array}$} & \multicolumn{2}{|c|}{$\begin{array}{c}\text { Calculation method used to } \\
\text { determine the cost-optimal } \\
\text { package of measures }\end{array}$} \\
\cline { 2 - 3 } & QSS & DD \\
\hline QSS & CO-QSS & $\begin{array}{c}\text { CO-DD } \\
\text { (QSS) }\end{array}$ \\
\hline DD & $\begin{array}{c}\text { CO-QSS } \\
\text { (DD) }\end{array}$ & CO-QSS \\
\hline
\end{tabular}

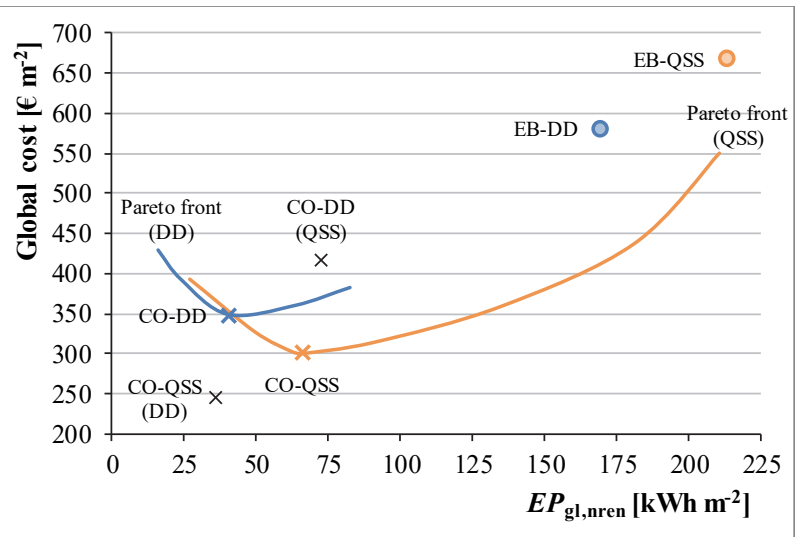

Figure 1: Global cost vs. energy performance.

As shown in Figure 1, the discrepancies, documented in several studies, between QSS and DD are evident in the energy performance assessment of the existing building (EB). That is because the QSS method tends to overestimate particularly the heating energy need, which represents the main energy service of the building. The Pareto fronts deriving from QSS and DD have a similar trend but they are shifted as concerns both overall nonrenewable primary energy and the global cost. It results that the optimization models identify two different "costoptimal packages of energy efficiency measures" (COs) and consequently different associated technologies, as reported in Table 4.

With regard to the single energy efficient measures on the reference building, the cost-optimal package identified by the optimization from QSS and DD methods are very similar as concern the building envelope insulation and solar control measures. Both the simulation-based optimization models identify as cost-optimal solutions a moderate level of insulation of external walls and windows as well as the installation of movable solar shading devices. Moreover, both calculation methods evaluate as cost-ineffective the choice of insulating the lower floor above the unconditioned space. The only difference between the two COs concerns the insulation of the upper floor. According to CO-QSS the upper floor has to be highly insulated considering the maximum EEO, whereas the CO-DD identifies the intermediate EEO, as for the other measures related to the opaque envelope. 
Table 4: Cost-optimal packages of energy efficiency measures of the design parameters.

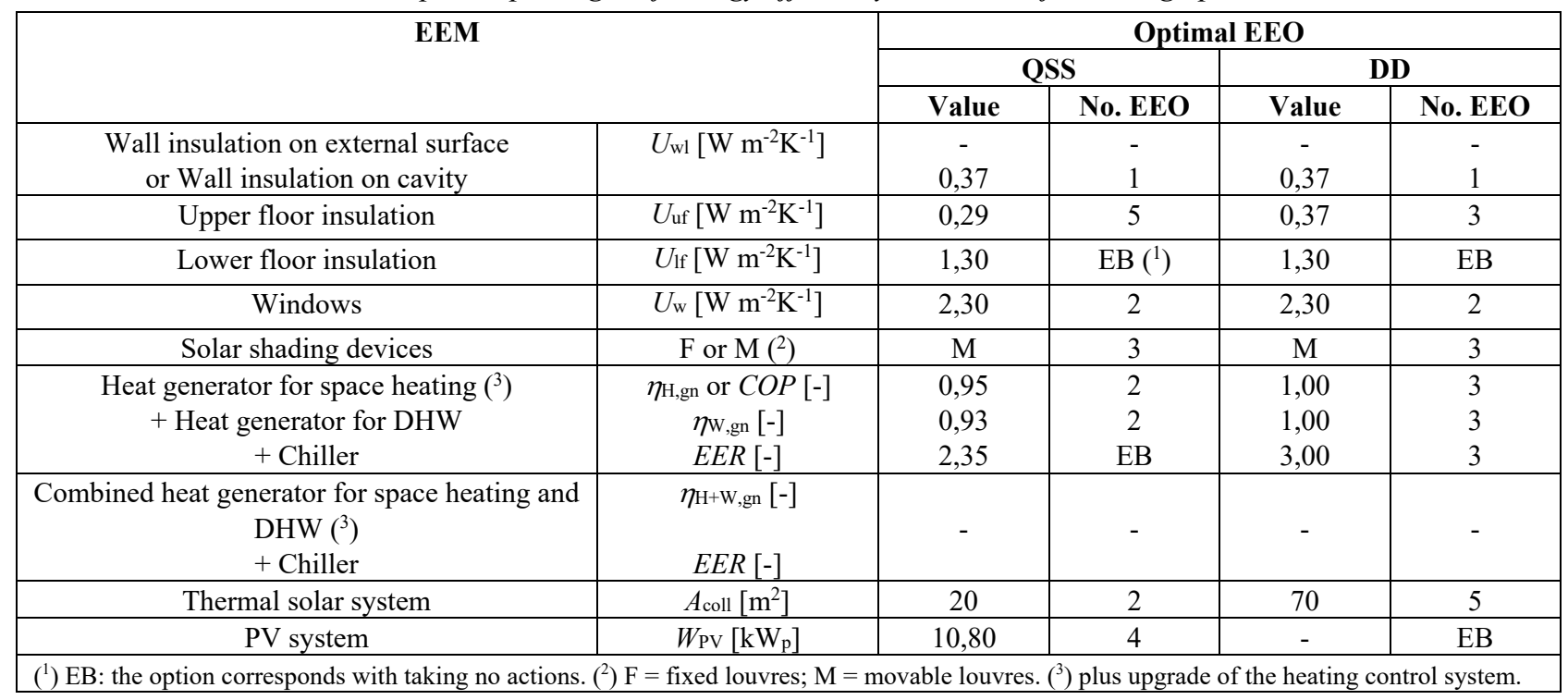

As regards the technical building systems and the use of renewable energy sources, the two $\mathrm{CO}$ solutions differ quite a lot. The QSS model selects standard boilers both for space heating and for DHW, with a scarce improvement of the existing generator efficiency. In particular, the choice of standard boiler for heating does not imply the replacement of the emission terminals. The cost-optimal package determined by quasi-steady-state calculation method (CO-QSS) does not include the replacement of the existing chiller.

Regarding the energy from renewable sources, the QSS method identifies as cost-optimal the installation of thermal solar system in the smallest extent and of PV system in the highest considered size. On the other hand, the DD simulation chooses in its cost-optimal package (CO-DD): the condensing boiler both for heating and DHW, the replacement of the radiators with fan coil units, and the installation of higher efficiency chiller. These thermal system technologies are combined with the highest size of thermal solar system and no PV systems. Both the optimization tools do not choose the heat pump for space heating.

In terms of overall non-renewable primary energy (Figure $2)$, the QSS method overestimates both the EB (+21\%) and especially the $\mathrm{CO}$ (around $+45 \%$ ) in comparison to DD. The CO-QSS reduces $E P_{\text {gl,nren }}$ of about $70 \%$ as compared to the EB-QSS. Similarly, the CO-DD saves $76 \%$ of overall non-renewable primary energy compared with the building before refurbishment (EB-DD).

As concerns the global cost (Figure 3), the initial investment, operating and maintenance costs are consistent between the models, for this reason the energy costs are fundamental to cost-optimization. The greatest saving comes from the application of CO-QSS (55\%) to EB-QSS rather than the CO-DD refurbishing the EB-DD $(40 \%)$.

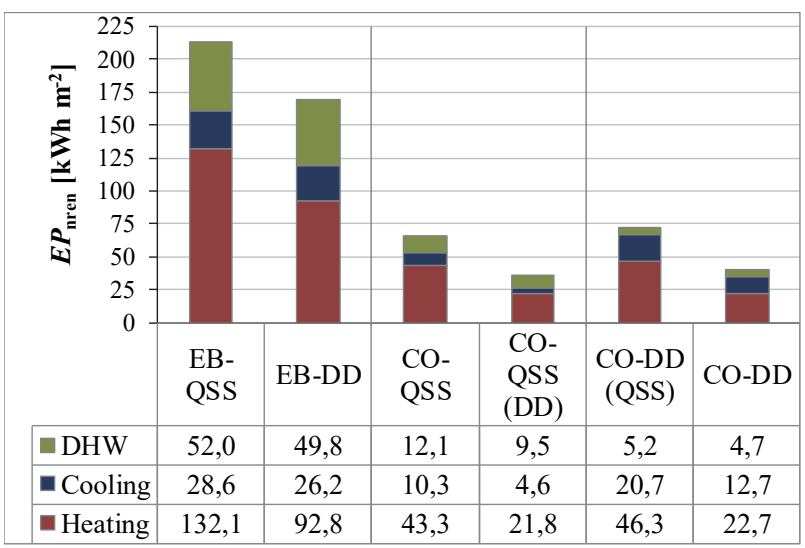

Figure 2: Overall non-renewable primary energy normalized by the conditioned floor area.

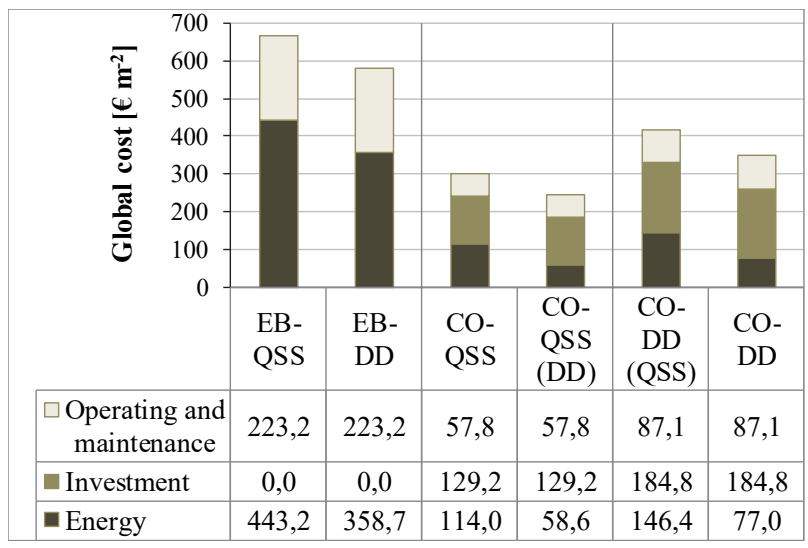

Figure 3: Global cost normalized by the conditioned floor area.

The trend of the QSS method to overestimate the heating energy with respect to DD is common to many building types. Nevertheless, the results of the present study about the choice of cost-optimal EEMs should be limited to the specific case study, i.e. an apartment block in a temperate 
climate, in which winter heat losses are the main term in the building energy balance.

\section{Conclusion}

Two different numerical simulation methods were investigated to perform the cost-optimal analysis: the monthly quasi-steady-state method coupled with a sequential search-optimization technique and the detailed dynamic simulation model combined with a multiobjective genetic algorithm.

Results highlight the relevance of the choice of the optimization method in the identification of cost-optimal package of energy efficiency measures and consequently, of the related technologies.

The outcomes of this activity suggest that States should accurately consider the adoption of the calculation method to identify the cost-optimal levels of minimum energy performance requirements for new buildings and existing buildings undergoing major renovations. Fundamentally, this aspect influences the subsequent national policies as well as other assumptions, such as the real interest rate, the energy costs, the technical lifespan of building components and technical building systems used in the calculation process.

The next steps of this study will be to increase the number of building types and of climatic conditions, in order to draw up general guidelines about the use of cost optimization in building design at national level.

\section{Nomenclature}

$\begin{array}{lll}\text { Symbol } & \text { Quantity } & \text { Unit } \\ A & \text { area } & \mathrm{m}^{2} \\ C O P & \text { coefficient of performance } & - \\ E E R & \text { energy efficiency ratio } & - \\ E P & \text { energy performance } & \mathrm{kWh} \cdot \mathrm{m}^{-2} \\ g & \text { total solar energy } & - \\ & \text { transmittance (solar factor) } & \\ H D D & \text { heating degree days } & { }^{\circ} \mathrm{C} \cdot \mathrm{d} \\ U & \text { thermal transmittance } & \mathrm{W} \cdot \mathrm{m}^{-2} \mathrm{~K}^{-1} \\ V & \text { volume } & \mathrm{m} \\ W & \text { peak power } & \mathrm{kW}\end{array}$

\section{Greek symbols}

\begin{tabular}{ll}
$\eta$ & efficiency \\
\multicolumn{2}{l}{ Subscripts } \\
C & space cooling \\
coll & solar collectors \\
d & distribution \\
e & emission \\
env & building envelope \\
f, fl & floor \\
g & gross \\
gl & glass, overall \\
gn & generation
\end{tabular}

$\begin{array}{ll}\text { H } & \text { space heating } \\ \text { lf } & \text { lower floor } \\ \text { net } & \text { net } \\ \text { nren } & \text { non-renewable } \\ \text { PV } & \text { photovoltaic system } \\ \text { sh } & \text { shading } \\ \text { uf } & \text { upper floor } \\ \text { W } & \text { domestic hot water } \\ \text { w } & \text { window } \\ \text { wl } & \text { wall }\end{array}$

\section{Acronyms and abbreviations}

$\mathrm{CO}$ cost-optimal package

DD detailed dynamic simulation method

DHW domestic hot water

F fixed louvres

EB existing building

EEM energy efficiency measure

EEO energy efficiency option

M movable louvres

NSGA non-dominated sorting genetic algorithm

PID proportional-integral-derivative

QSS quasi-steady-state calculation method

\section{References}

Christensen, C., Anderson, R., Horowitz, S., Courtney, A. and J. Spencer (2006). BEoptTM software for building energy optimization: features and capabilities. U.S. Department of Energy, NREL. Golden (USA).

Corrado, V., Ballarini, I. and S. Paduos (2014a). Assessment of cost-optimal energy performance requirements for the Italian residential building stock. Energy Procedia 45, 443-452.

Corrado, V., Ballarini, I. and S.P. Corgnati (2014b). Fascicolo sulla Tipologia Edilizia Italiana-2 ${ }^{\text {nd }}$ edition. Politecnico di Torino. Torino (Italy). (in Italian).

Deb, K., Pratap, A., Agarwal, S. and T. Meyarivan (2002). A fast and elitist multiobjective genetic algorithm: NSGA-II. IEEE transactions on evolutionary computation 6-2, 182-197.

DesignBuilder - https://www.designbuilder.co.uk/

European Committee for Standardization (2017). Energy performance of buildings - Economic evaluation procedure for energy systems in buildings - Part 1: Calculation procedures, Module M1-14 (EN 15459).

European Union (2012a). Guidelines accompanying Commission Delegated Regulation (EU) No 244/2012 of 16 January 2012 supplementing Directive 2010/31/EU of the European Parliament and of the Council on the energy performance of buildings by establishing a comparative methodology framework 
for calculating cost-optimal levels of minimum energy performance requirements for buildings and building elements. Official Journal of the European Union.

European Union (2012b). Commission Delegated Regulation (EU) No 244/2012 of 16 January 2012 supplementing Directive 2010/31/EU of the European Parliament and of the Council on the energy performance of buildings by establishing a comparative methodology framework for calculating cost-optimal levels of minimum energy performance requirements for buildings and building elements. Official Journal of the European Union.

European Union (2010). Directive 2010/31/EU of the European Parliament and of the Council of 19 May 2010 on the energy performance of buildings (recast). Official Journal of the European Union.

Evins, R. (2013). A review of computational optimisation methods applied to sustainable building design. Renewable and Sustainable Energy Reviews 22, 230245.

Hamdy, M., Nguyen, A. and J. Hensen (2016). A performance comparison of multi-bjective optimization algorithms for solving nearly-zeroenergy-building design problems. Energy and Buildings 121, 57-71.

Harkouss F., Fardoun F. and P.H. Biwole (2018) Multiobjective optimization methodology for net zero energy buildings. Journal of Building Engineering 16, $57-71$.

Italian Ministry of Economic Development (2015). Decree of the Italian Ministry of Economic Development 26 June 2015. Application of calculation methodologies of the building energy performance and definition of minimum energy performance requirements. (in Italian).
Italian Ministry of Economic Development (2018). Update of the application in Italy of the method for calculating cost-optimal levels for minimum energy performance requirements (Directive 2010/31/EU Article 5). (in Italian)

Italian Organisation for Standardisation $(2010 \div 2016)$. Energy performance of buildings (UNI/TS 11300 series).

Italian Thermotechnical Committee (2016). Test reference years for thermotechnical applications. http://try.cti2000.it/.

Longo, S., Montana, F. and E. Riva Sanseverino (2019). A review on optimization and cost-optimal methodologies in low-energy buildings design and environmental considerations. Sustainable Cities and Society 45, 87-104.

Machairas, V., Tsangrassoulis, A. and K. Axarli (2014). Algorithms for optimization of building design: A review. Renewable and Sustainable Energy Reviews 31, 101-112.

Nguyen, A., Reiter, S. and P. Rigo (2014). A review on simulation-based optimization methods applied to building performance analysis. Applied Energy 113, 1043-1058.

Sharif, S.A. and A. Hammad (2019). Simulation-Based Multi-Objective Optimization of institutional building renovation considering energy consumption, LifeCycle Cost and Life-Cycle Assessment. Journal of Building Engineering 21, 429-445.

Si, B., Tian, Z., Chen, W., Jin, X., Zhou, X. and X. Shi (2019). Performance Assessment of Algorithms for Building Energy Optimization Problems with Different Properties. Sustainability 11-18. 